\title{
The source of keypecking in autoshaping*
}

\author{
ELKAN GAMZU \\ Hoffmann-La Roche, Inc., Nutley, New Jersey 07110 \\ and \\ DAVID R. WILLIAMS \\ University of Pennsylvania, Philadelphia, Pennsylvania 19104
}

\begin{abstract}
Pigeons were trained to step on a treadle to operate a grain hopper, under the control of an auditory stimulus. Subsequently, autoshaping consisted of pairing illumination of a response key with some of the subsequent tone presentations, reinforcement occurring only after a treadle response. One control group did not have a treadle or a treadle-response requirement. A second control group received random presentations of an illuminated key. Neither paired nor random key presentations had any effect on treadlepressing. However, the paired key groups showed acquisition of pecking to the key, while the random group did not. The data suggest that pecking in the autoshaping procedure is not profitably analyzed as part of an operant sequence and it indicates that autoshaping involves a structuring of response repertoires that may well be independent of the effects of contingent reinforcement and shaping. Autoshaping seems to be governed by empirical temporal laws akin to those of classical conditioning.
\end{abstract}

In the autoshaping procedure developed by Brown and Jenkins (1968), illumination of a response key signaled the forthcoming presentation of grain. In virtually all pigeons tested, the procedure reliably and efficiently led to the initiation of pecking. The use of appropriate control groups indicated that the stimulus-reinforcer pairing was a crucial feature of autoshaping. The singular effectiveness of the key-food pairings has since been demonstrated by the finding that pigeons continue to peck frequently on the illuminated key even when pecking at the key prevents reinforcement (Williams \& Williams, 1969). Furthermore, when grain is presented independently of responding, the key-food relationship controls the presence or absence of pecking (Gamzu \& Williams, 1971, 1973). Jenkins (1973) has concluded that even a most liberalized modified version of the operant principle cannot encompass all the data on autoshaping. Although there is some dispute about the nature of the process underlying the control exerted by the stimulus-reinforcer relationship (see, for example, Moore, 1973 and Jenkins, 1973 for two different points of view), the fact that the key-food relationship plays a major role in autoshaping procedures is not in doubt. Moreover, this seems to be related to the fact that pecking at visual stimuli is a normal part of the feeding pattern in adult pigeons. The theoretical explanation of these facts is complicated by the fact that there appears to be no generally accepted framework in which even

\footnotetext{
*This work was supported by a Grant, G14055, from the National Science Foundation, to David R. Williams. The work was conducted while the first author was at the University of Pennsylvania. We are grateful to Tom Allaway, Joe Bernheim, Linda Conner, Zelda Gamzu, Elias Schwam, Barry Schwartz, Alan Silberberg, Harriet Williams, and Kit Zonana for help in various stages of the preparation of this paper. Reprint requests should be addressed to Dr. Elkan Gamzu, Hof fman-La Roche, Inc., Pharmacology Department, Nutley, New Jersey 07110.
}

the peck directed at food would unambiguously be classified as "consummatory" rather than "instrumental."

Autoshaping of a response that does not appear to be consummatory in nature has been demonstrated in rhesus monkeys (Sidman \& Fletcher, 1968) and in squirrel monkeys (Gamzu \& Sclıwam, 1974). In both cases, the monkeys pressed the illuminated key in procedures virtually identical to that used by Brown and Jenkins (1968). Sidman and Fletcher (1968, pp. 308) pointed out that "Although the monkey used its fingers both to press the key and to pick up the pellet, the topography of these two behaviors is quite different." Moreover, unlike pecking in the pigeon, use of the forelimbs in monkeys is not a necessary behavior for ingestion of food. The question we posed was whether autoshaped pecking in the pigeon would occur when the behavioral chain leading to ingestion of grain is altered by the introduction of a nonvisual stimulus and a clearly "nonconsummatory" response.

The general plan of the experiment was to bring a treadle response (that is not normally part of the feeding pattern of behavior) under strong discriminative control of an auditory stimulus; the sequence of events was tone presentation, then treadle response, then food presentation. Subsequently, illumination of the key was paired with the tone presentation in such a fashion that the key predicted the forthcoming auditory stimulus, but conveyed no additional information about the availability of food. One control group received key illuminations that were random with respect to the tone (Rand). A second group received the same stimulus sequences that the experimental group received but without a treadle-response requirement (No-Tread).

The procession of events: (1) illuminated key, (2) treadle response, (3) pecking, and (4) ingestion, 
STAGE I

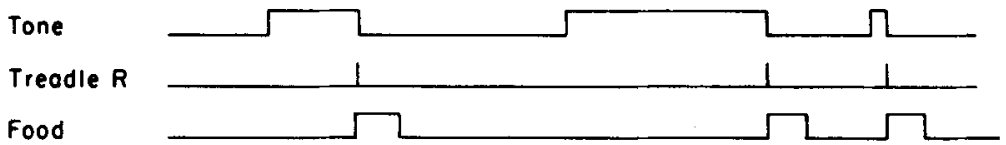

Food

STAGE II Experimental Group

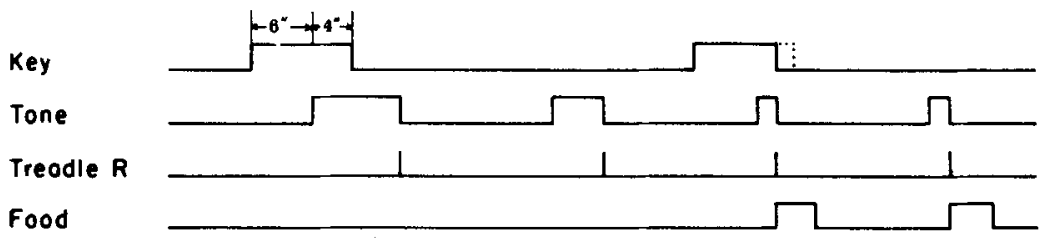

Fig. 1. A schematic representation of procedures used. In Stage I, discriminative auditory control over a treadlepress was established. In Stage II, autoshaping consisted of pairing illumination of a key with presentation of the tone. See text for further explanation. resembles the pattern of events in the studies of autoshaping in monkeys: (1) illuminated key, (2) manipulation response, (3) chewing, and (4) ingestion. In terms of the stimuli-response sequences, the experiment is similar to the Brown and Jenkins (1968) study. In the latter, $S_{1}$ (the illuminated key) precedes $S_{2}$ (grain presentation) that elicits pecking, while in the present study $S_{1}$ (the illuminated key) precedes $S_{2}$ (the tone) that elicits treadle pressing. Consequently, if the key-tone pairings were to engender treadle responding, it would appear that the phenomenon of autoshaping involves the elicitation of a strong operant (even though the process is not explained by the operant principle) in the pattern of behavior leading to ingestion of grain. To the extent that autoshaping of keypecking in pigeons is related primarily to the occurrence of feeding; however, pecking alone would develop when illumination of the key was followed by tone presentations, since the tone is classically paired with the grain presentation.

\section{METHOD}

\section{Subjects}

Twelve experimentally naive male Silver King Pigeons were deprived and maintained at $80 \%$ of their free-feeding weight.

\begin{abstract}
Apparatus
The pigeon chamber was $33 \times 33 \times 30.5 \mathrm{~cm}$. One wall housed a standard three-key Lehigh Valley pigeon panel. The center key and the houselight could be illuminated by No. 1829 bulbs operated at $20 \mathrm{Vdc}$. The keys were $21.6 \mathrm{~cm}$ above the floor of the compartment, and the grain hopper was centered $12.7 \mathrm{~cm}$ below the middle key. In addition, an aluminum foot treadle, $25.4 \mathrm{~cm} \times 10.2 \mathrm{~cm}$ in area and mounted $2.5 \mathrm{~cm}$ above the floor, was placed.at the back of the chamber. A static force of $70 \mathrm{~g}$, applied to the surface of the treadle, operated a recording switch. The placement of the treadle was chosen to minimize cooccurrences of treadle standing with either feeding or pecking, and we were unable to notice any instances where this occurred. Automatic programming and recording equipment were located in an adjacent room.
\end{abstract}

\section{Proced ure}

The 12 pigeons were randomly assigned to three groups of 4 pigeons in each. Certain aspects of the procedures were common to all stages of the experiment for all groups. Intertrial intervals ranged from 10 to $90 \mathrm{sec}$ in units of $10 \mathrm{sec}$ and had an approximately geometric distribution with a mean of $30 \mathrm{sec}$. A moderately loud $1,000-\mathrm{Hz}$ tone was used as the auditory discriminative stimulus that defined the trials. Reinforcement consisted of 4-sec access to mixed grain. At no point in the experiment did pecking at the key have any programmed consequences.

Prior to the initiation of the experiment, all birds were given 2 days of magazine training; 50 reinforcements were made available randomly in time and indepently of the birds' behavior on each day. On the third day, appropriate experimental procedures were instituted.

Stage I: Discriminative Auditory Control. During the first session of this procedure, the pigeons in the experimental (E) and random control (Rand) groups were shaped by the method of successive approximations to depress the treadle by stepping on it. During the next eight daily sessions, the treadle response was brought under discriminative control of the tone. Each session consisted of 50 trials, which were initiated by the presentation of the tone and lasted until the pigeon made a treadle response, at which point reinforcement was delivered and the tone terminated. Treadlepresses in the intertrial interval delayed the onset of the subsequent trial by a variable delay with a mean of $10 \mathrm{sec}$. A schematic presentation of this procedure is presented in the upper portion of Fig. 1.

The second control group (No-Tread) did not have a treadle in the chamber. For this group, food was presented at the end of the tone trials, the duration of which was chosen to resemble as closely as possible the tone durations noted for the E and Rand groups. This was an approximately gamma distribution with a mode of 4 sec.

Stage II: Key Probes. In this stage of the experiment, only $50 \%$ of the trials terminated in food presentation, but 100 trials were presented each day. As in the earlier stage, trial duration was variable, termination being determined by a treadle response for the $E$ and $R$ and groups and according to the appropriate gamma distribution for the NoTread group. In addition, 20 key probes were presented each day. For the first nine sessions, the key was not illuminated during the various portions of the experiment. Since there was no corresponding event to the probe in the chamber, the pigeons were essentially in the same procedure as in Stage $I$, with the exception of the $50 \%$ reinforcement schedule. This will be referred to as the baseline probe procedure. On the tenth session of this stage, the key was illuminated during the probes. This procedure was in effect for nine sessions. Each group received only one of the following pattern of probes throughout both the baseline and illuminated probe procedures.

Paired Key Probes (Autoshaping). Both the $\mathrm{E}$ and the No-Tread groups received this type of probe. On 20 occasions in 
each session, the key was presented $6 \mathrm{sec}$ prior to the tone, which had been established as a discriminvative stimulus. The tone was terminated by a treadlc response (or gamma distribution) as before. Four seconds overlap between the key and tone presentations were provided unless a treadle response occurred within that period, in which case both stimuli were turned off and reinforcement delivered if scheduled. The actual location of the key probes within the 100 trials was random, with the limitation that $50 \%$ of these trials be followed by food. A schematic representation of this procedure is shown in the lower portion of Fig. 1. It should be noted that by use of the partial reinforcement schedule and randomization of the location of the probes, the key predicted that the tone was about to be presented but did not predict whether food would be available; i.e., given the tone, food presentation had the same probability with or without key illumination.

Random (Nonpaired) Key Probes. The random group also received a mean of 20 key probes each session, but these were presented randomly in time and thus did not signal any experimental event. Again, the key presentation lasted for $10 \mathrm{sec}$ unless a treadle response occurred in a period in which tone and key stimuli overlapped, in which case both stimuli were terminated.

\section{RESULTS}

Since the duration of the key presentations varied slightly with the individual pigeon's treadle behavior, the results are presented in terms of the number and percent of illuminated key probes with at least one response. The effects described below are of greater magnitude when response rates are the measure, but since our main concern was the presence or absence of the keypeck and/or the treadle response during illumination of the key, we adopted the more conservative measure.

The introduction of the illuminated key probes, either paired (autoshaping) or random, had virtually no effect on the treadle-pressing behavior. This can be seen in Fig. 2. The left half of the figure shows the base rate of treadle responding during key probes for the nine sessions of the baseline procedure. For both groups, treadle responding in this portion of the session was very infrequent. This was true even after the illuminated

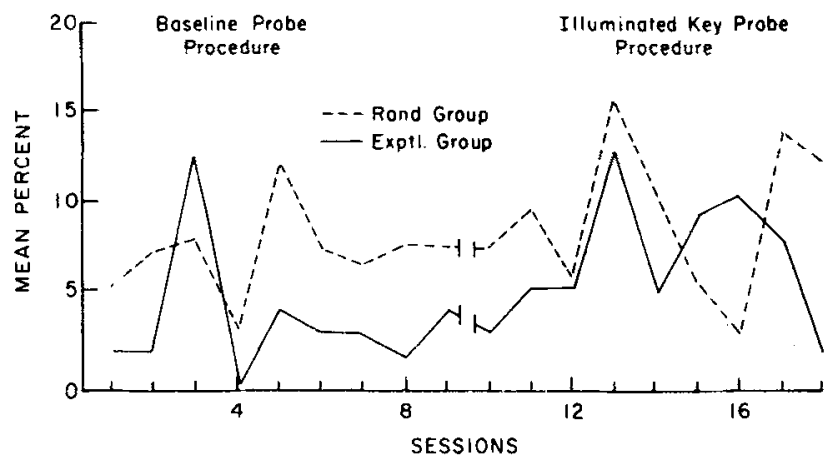

Fig. 2. The mean percent of daily key probes during which at least one treadle-press was recorded, before and after autoshaping. For the experimental group, the illuminated key and the tone were paired; for the Rand group, they were randomly related.

key probes were introduced, as can be seen in the right half of the figure. Statistical analysis failed to reveal reliable differences in treadle performance before and after the introduction of the autoshaping and control procedures $(p>.13$ for Group E; $p>.48$ for Group Rand). Inspection of treadle responding during the intertrial interval was consistent with this observation; there was no evidence of an increase in responding in either group.

The systematic pairing of key and tone had a marked effect on keypecking, however, as can be seen in Fig. 3, which plots the percent of 20 daily key probes duirng which at least one keypeck was observed. Groups $E$ and No-Tread, both of which received paired presentations of key illumination and tone, showed acquisition of pecking to the key when it was illuminated. Pecking of the key did not develop in Group Rand, however, where key illumination and tone presentations were only randomly related. The increase in pecking for Groups $\mathrm{E}$ and No-Tread during key illumination was statistically

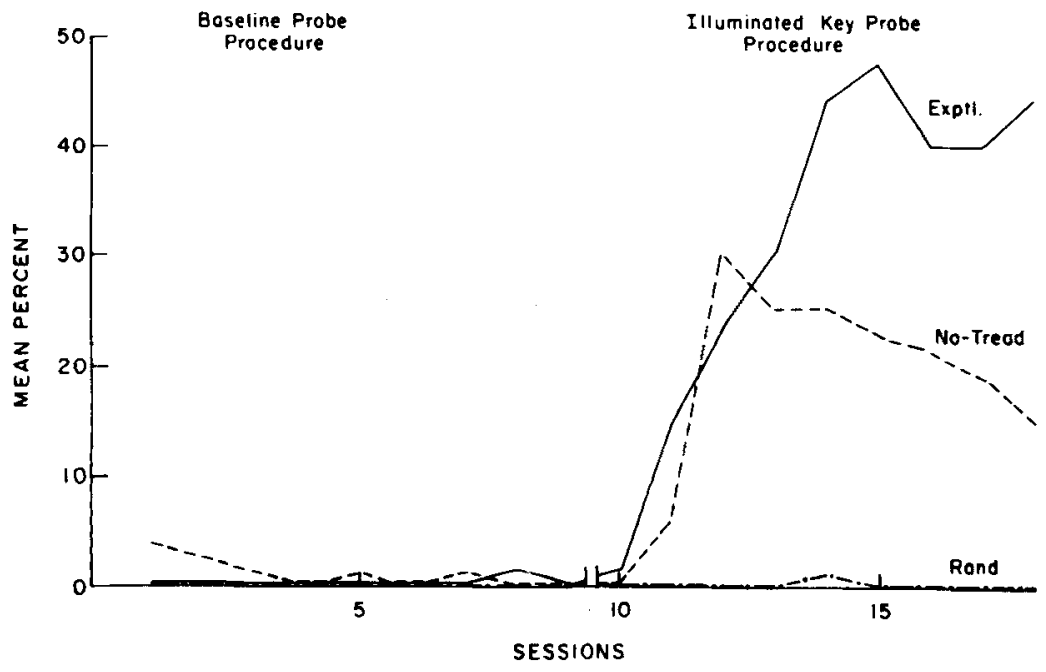

Fig. 3. The mean percent of daily key probes during which at least one keypeck was recorded, before and after autoshaping. For the experimental group, the illuminated key and the tone were paired; for the Rand group, they were randomly related. 


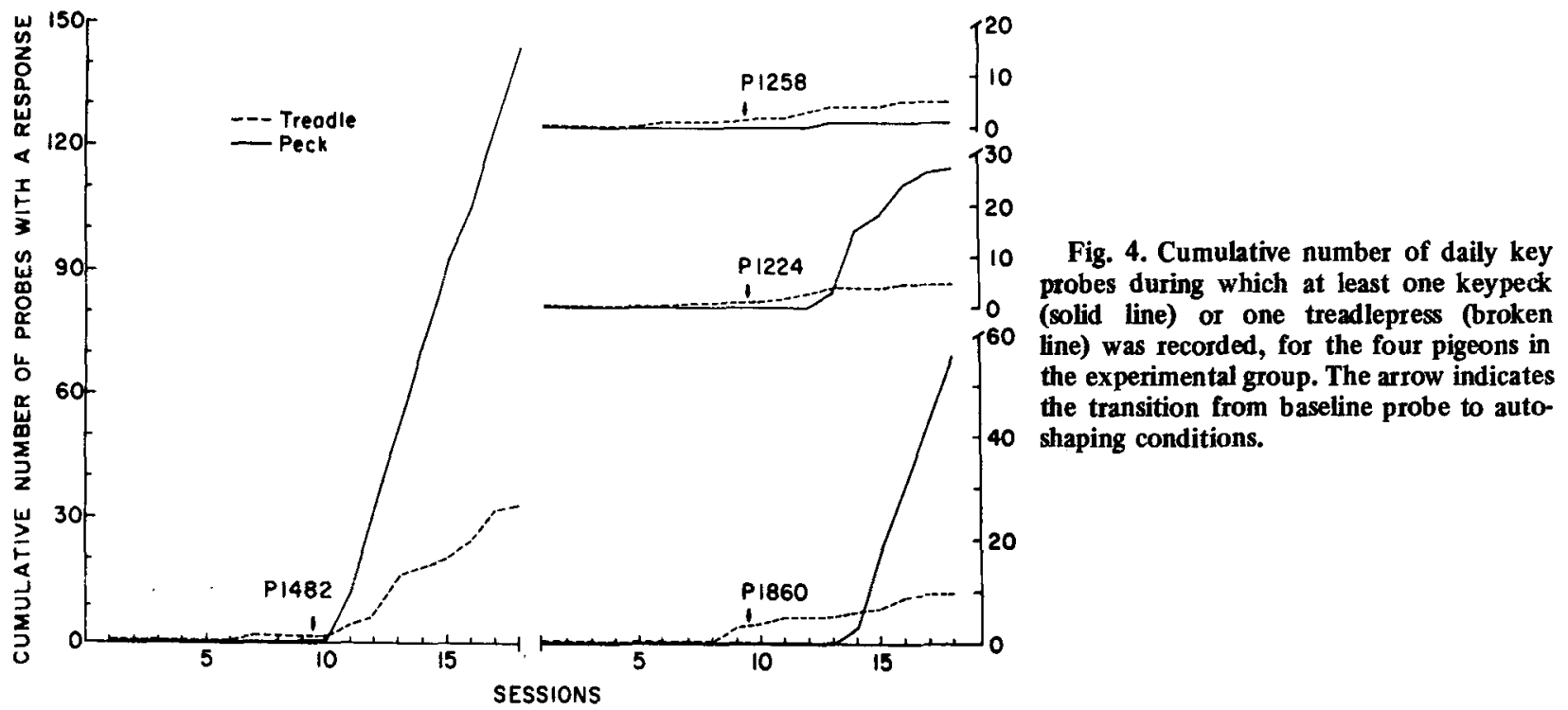

reliable $(\mathrm{p}<.001$ and $\mathrm{p}<.003$, respectively, Mann-Whitney one-tailed tests).

The contribution of individual birds in the experimental group to the group data is shown in Fig. 4. Figure 4 presents separate cumulative curves of trials on which at least one response (the the key or treadle) occurred, over daily sessions of $20 \mathrm{key}$ presentations for each bird of the experimental group. The arrows indicate the point of transition from baseline to autoshaping conditions. Three of the four birds pecked at the key consistently, although the rate of Bird 1224 began to falter in Session 6. P 1258 made only one peck at the illuminated key. P 1482 provided the only evidence of a substantial increase in treadle responding; this increase was evident only after the bird started pecking on the key at a high rate and did not appear to interfere with his rate of pecking.

The effect of autoshaping trials on individual birds in Group NoTread is shown in Fig. 5. The individual differences in this group are quite striking. Two birds showed no evidence of pecking at the key, one (P 253) showed substantial pecking throughout the experimental period, and the fourth began pecking, but the response declined in frequency as the series of sessions continued. It is interesting to note that P 253 made a substantial number of pecks during the sham-key presentations. Since there was no corresponding stimulus event in the experimental chamber during this time, the result is indicative of a high operant rate of pecking.

\section{DISCUSSION}

The experimental procedure used in this study resulted in autoshaping of the keypecking response, and not in autoshaping of treadlepressing. The key signaled that a trial would be forthcoming and, therefore, was regularly followed by a treadle response. Because key presentations were random with regard to the

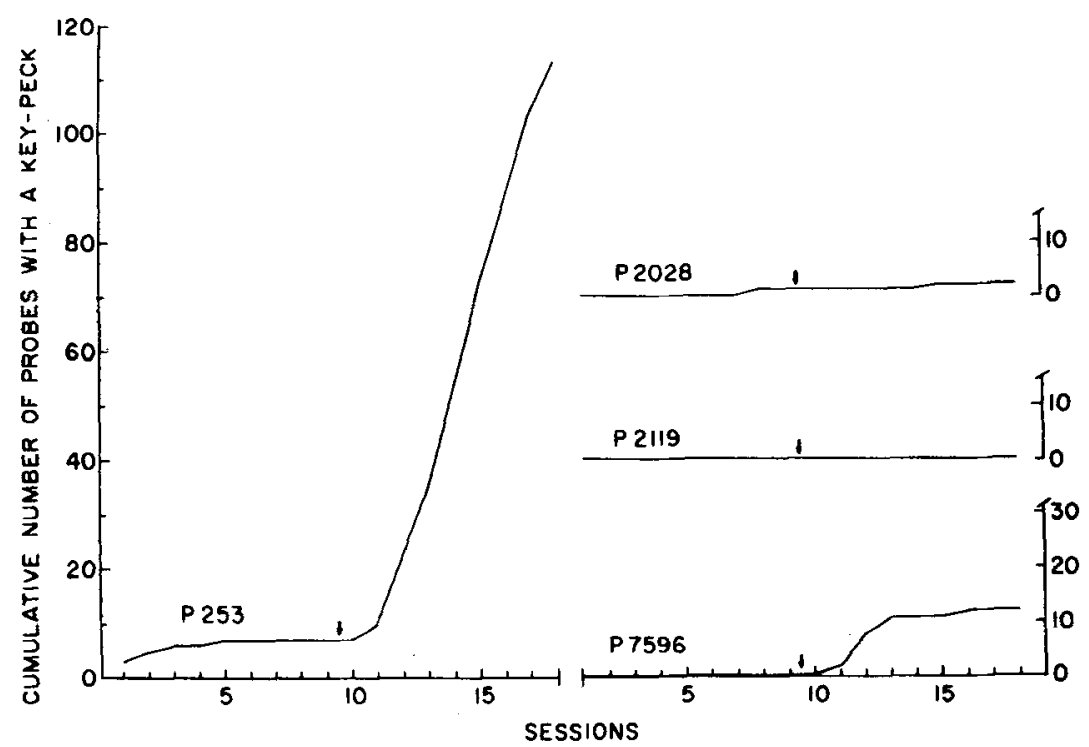

Fig. 5. Cumulative number of daily key probes during which at least one keypeck was recorded for the four pigeons in the No-Tread group. The arrow indicates the transition from baseline probe to autoshaping conditions. 
availability of reinforcement on tone trials, key presentations were followed by feeder-directed pecking only $50 \%$ of the time. Had the pattern of key presentations and reinforcement occurred without the intervening tone/treadle condition, at the most only $20 \%$ of the reinforcers would have been immediately preceded by the key. The other $80 \%$ of the reinforcers would have been unsignaled. Because the tone trials were terminated response dependently, the actual temporal relations between key illumination and food presentation cannot be specified. However, it seems doubtful that any pecking at all would have developed to the illuminated key in such a variable trial procedure; the procedure bears some similarity to Gamzu and Williams's $(1971,1973)$ nondifferential procedure that fails to produce autoshaped keypecking and actually eliminates already established keypecking. Thus, we doubt that the acquisition of keypecking in this experiment can be attributed to the relationships between the illuminated key and food presentations.

Another source of evidence that the illuminated key-tone pairings are crucial to the present effect comes from research that indicates that the consistent signaling of food presentations by tones can prevent or attenuate autoshaping of keypecking in pigeons. Allaway (1971) found that the acquisition of keypecking in an autoshaping procedure was greatly attenuated and - sometimes blocked if a tone always preceded the key illumination, presumably because the latter was redundant in predicting the presentation of food. Gamzu (1968) used a procedure in which tone presentations always preceded access to food. Every so often the pecking key was illuminated just before, just after, at the same time as, or separately from the tone trials. Pecking at the key did not develop. Indeed, this procedure eliminated keypecking that had been previously established. In the present experiment, each food presentation was preceded by a tone, yet pecking did develop. In view of the cited results, this outcome is best attributed to the pairing of key illumination with tone presentation.

Finally, the difference in rate of keypecking between the $E$ and Rand presentation groups shows that the systematic pairing of the key and tone was an essential aspect of the present procedure.

Although there was little evidence that treadle jumping was facilitated in the presence of the illuminated response key, the speed and reliability of treadle jumping during the tone is a convincing indicator that treadle jumping was under reliable discriminative control.

From an instrumental stand point, treadle jumping was no less important than pecking at grain; each response was necessary for successful completion of the pattern of behavior that led to ingestion. It seems clear, therefore, that pecking has a special status in the autoshaping situation and is not profitably analyzed as one of a number of operant responses which happen to be present and have an opportunity to occur in the autoshaping situation.

The failure of the treadle operant to compete with keypecking was not due to lack of availability of the manipulandum, nor to poor control by the reinforcement contingency. Moreover, pecking at the key was inefficient, in the sense that once the tone was presented, the bird had to cross the chamber to the treadle, respond there, and then return to the feeder. Comparison of the E group with the No-Tread group suggests that pecking on the key was enhanced by the availability of the competing operant response. A similar effect has been reported by Engberg, Hansen, Welker and Thomas (1973) who implied that this was a result of "learned industriousness." However, their explanation has been attacked on both methodological and theoretical grounds (Gamzu, Williams, \& Schwartz, 1973). Moreover, since pecking is entirely irrelevant and even inefficient in this experiment, it is difficult to see how the Engberg et al (1973) explanation could even be applied. Rather, we feel that the enhancement of responding in the group for which the treadle operant was required resembles the result reported by Ferster (1953), who showed that the effect of a delay in reinforcement is attenuated if a reliable behavior pattern spans the delay interval. Finally, the occurrence of substantial and vigorous autoshaped pecking in the $\mathrm{E}$ group demonstrates that pecking in the ordinary autoshaping situation is not simply due to the normal lack of alternatives provided by the relatively impoverished environment of the "Skinner box"; in these experiments, there was a viable, operant alternative to pecking the key, and the treadle was physically no less available in the presence of the illuminated key than was the illuminated key period itself.

Strictly speaking, the procedure used in the NoTread group, and the stimulus characteristics of the procedure in the $\mathrm{E}$ group, resemble Pavlovian "higher order conditioning." Classical conditioning in this type of procedure is weaker than in conventional Pavlovian conditioning (Pavlov, 1929). We feel that the tendency of some birds in this experiment to show less consistent pecking than birds trained under the ordinary autoshaping conditions may well arise from the use of this type stimulus-reinforcer relationship.

The effects described in this paper, together with those cited, suggest that a process relating classical conditioning to feeding behavior is involved in autoshaping of keypecking in the pigeon (cf. Moore, 1973). Indeed, the procedure has already been used to study stimulus-reinforcer relationships and their interactions with operant control in nonaversive situations (see, for example, Gamzu and Schwartz, 1973,; Redford \& Perkins, 1974; Schwartz, 1973; and Wessells, 1973). While the procedural similarity between classical conditioning and autoshaping is part of the basis 
of this conclusion, paradigmatic similarity by itself is insufficient to infer control by stimulus-reinforcer relations. In squirrel monkeys, for example, the autoshaping procedure results in keypressing; however, not only are a number of aspects of the results different from autoshaping in the pigeon, but the keypress is not maintained when it prevents the delivery of food (Gamzu \& Schwam, 1974). Thus, although something like classical conditioning may play a role in autoshaping with squirrel monkeys, the actual response is not as clearly controlled by the key-food relationship, and the keypress in squirrel monkeys at least would not be as good an index of the stimulus-reinforcer dimension of control of behavior as the keypeck in pigeons.

The present experiment adds another dimension to the published data that indicate that the occurrence of pecking in the autoshaping situation is not a straightforward expression of operant principles (Gamzu \& Williams, 1971, 1973; Herrnstein \& Loveland, 1972; Moore, 1973; Jenkins, 1973; Jenkins \& Moore, 1973; Schwartz \& Williams, 1972a, b; and Williams \& Williams, 1969 , for further evidence on this point).

Although his theory dealt primarily with adaptive learning in situations involving reward, in Postulate 3 , Hull (1943) acknowledged that responses are not selected randomly from an organism's repertoire. This problem-the structuring of a response repertoire in the early stages of learning, before contingent reinforcement and shaping are major determinants of performance-has been described largely in terms of unlearned predispositions and generalization from prior operant situations. It would be strange indeed if adaptive mechanisms of learning did not exploit the availability of processes other than those directly related to reward and punishment (Bolles, 1970; Falk, 1971; Segal, 1972; Seligman, 1970; Seligman \& Hager, 1972; Shettleworth, 1972; Staddon \& Simmelhag, 1971). We suspect that autoshaping represents a case where aspects of the pigeon's repertoire are differentially strengthened through learning, independently of the effect of outcomes (Williams \& Williams, 1969). Whether all alignments of response repertoires prior to the operation of outcomes follow laws of classical conditioning in the straightforward manner encountered in this situation is a matter for further research. The study of autoshaping, however, may cast new light on an important mechanism of adaptive learning that has too long been neglected.

\section{REFERENCES}

Allaway, Thomas A. Attention, information, and autoshaping Unpublished Doctoral Dissertation, University of Pennsylvania, 1971.

Bolles, R. C. Species-specific defense reactions and avoidance learning. Psychological R eview, 1970, 77, 32-48.

Brown, P. \& Jenkins, H. M. Autoshaping of the pigeon's key-peck. Journal of the Experimental A nalysis of Behavior, $1968,11,1-8$.

Engberg, L. A., Hansen, G., Welker, R. L., \& Thomas, D. R Acquisition of key-pecking via autoshaping as a function of prior experience: "Learned laziness"? Science, 1973, 178, 1002-1004.

Falk, J. L. The nature and determinants of adjunctive behavior. Physiology \& Behavior, 1971, 6, 577-588.

Ferster, C. B. Sustained behavior under delayed reinforcement. Journal of Experimental Psychology, 1953, 45, 2, 8-224,

Gamzu, E. The classical conditioning paradigm in the "Autoshaping" of the pigeon's key-peck. Unpublished Master's thesis, University of Pennsylvania, Psychology Department, 1968.

Gamzu, E., \& Schwam, E. Autoshaping and automaintenance of a key-press response in squirrel monkeys. Journal of the Experimental Analysis of Behavior, 1974, 21, 361-371.

Gamzu, E., \& Schwartz, B. The maintenance of keypecking by stimulus-contingent and response-independent food presentation. Journal of the Experimental Analysis of Behavior, 1973, 19, 65-72.

Gamzu, E., \& Williams, D. R. Classical conditioning of a complex skeletal act. Science, 1971, 171, 923-925.

Gamzu, E. R., \& Williams, D. R. A ssociative factors und erlying the pigeon's key-pecking in autoshaping procedures. Journal of the Experimental Analysis of Behavior, 1973, 19, 223. 232.

Gamzu, E. R., Williams, D. R. \& Schwartz, B. Pitfalls of organismic concepts. Science, 1973, 181, 367-368.

Herrnstein, R., \& Loveland, D. Food avoidance in hungry pigeons and other perlexities. Journal of the Experimental A naly sis of Behavior, $1972,18,369-383$

Hull, C. L. Principles of behavior. New York: Appleton-Century-Crofts, 1943.

Jenkins, H. M. Effects of the stimulus-reinforcer relation on selected and unselected responses. In $\mathbf{R}$. A. Hinde and $\mathbf{J}$ Stevenson-Hinde (Eds.), Constraints on learning. New York: Academic Press, 1973. Pp. 189-206.

Jenkins, H, M. \& Moore, B, R. The form of the autoshaped response with food or water reinforcers. Journal of the Experimental A nalysis of Behavior, 1973, 20, 163-181.

Moore, B. R. The role of directed Pavlovian reactions in simple instrumental learning in the pigeon. In $R$. A. Hinde and $J$. Stevenson-Hinde (Eds.), Constraints on learning. New York: A cad emic Press, 1973. Pp. 159-188.

Pavlov, I. P. Conditioned reflexes. London: Oxford University Press, 1927

Redford, M. E., \& Perkins, C. C. The role of autopecking in behavioral contrast. Journal of the Experimental Analysis of Behavior, 1974, 21, 145-150.

Schwartz, B. Maintenance of keypecking by response-independent food presentation: The role of the modality of the signal for food. Journal of the Experimenta A nalysis of Behavior, 1973, 20, 17-22.

Schwartz, B., \& Williams, D. $R$. The role of the response-reinforcer contingency in negative auto-maintenance. Journal of the Experimental A nalysis of Behavior, 1972a, 17, 351-357.

Schwartz, B \& Williams, D. R. Two different kinds of key peck in the pigeon: Some properties of responses maintained by negative and positive response-reinforcer contingencies. Journal of the Experimental Analy sis of Behavior, 1972b, 18 , 201-216.

Segal, E. Induction and the provenance of operants. In $R$. $M$ Gilbert and J. R. Millenson (Eds.), Reinforcement: Behavioral analysis. New York: Academic Press, 1972. Pp. 1-34.

Seligman, M. E. P., On the generality of laws of learning. Psychological R eview, 1970, 77, 406-418.

Seligman, M. E. P., \& Hager, J. L. Biological boundaries of learning. New York: Appleton-Century-Crofts, 1972.

Shettlew orth, S. Constraints on learning. In D. S. Lehrman, R. A. Hinde, and E. Shaw (Eds.), Advances in the study of behavior Vol. 4, New York: Academic Press, 1972.

Sidman, M. \& Fletcher, F. G. A demonstration of autoshaping with monkeys. Journal of the Experimental A nalysis of Behavior, 1968, 11, 307.309.

Staddon, J. E. R., \& Simmelhag, V. L. The "superstition" experiment: A reexamination of its implications for the principles of adaptive behavior. Psychological Review, 1971, $78,3-43$.

Wessells, M, Errorless discrimination, autoshaping, and conditioned inhibition. Science, 1973, 182, 941-943.

Williams, D. R. \& Williams, H. Auto-maintenance in the pigeon: Sustained pecking despite contingent non-reinforcement. Journal of the Experimental A nalysis of Behavior, 1969, 12. 511-520.
(R eceived May 1, 1974; revision accepted August 7,1974 .) 